\title{
A study on the dynamic correlation between bond market and stock
}

\author{
market \\ Mingwei Zhou*, Yuan Zhang \\ School of Economic and Management in Nanjing University of Science and Technology, \\ China \\ *Corresponding author:Mingwei Zhou, Associate Professor, zhoumw@163.com
}

\begin{abstract}
Based on the dynamic theory of stock market and bond market, this paper chooses corporate bond index and CSI 300 index, and uses the co-integration test of EG two-step method, Granger causality hypothesis test and impulse response to analyze the correlation of stock market and bond market. The results show that: first, there is no cointegration relationship between the bond market and the stock market; second, there is a one-way Granger causality between the bond market and the stock market; third, from the perspective of impulse response and variance decomposition, the bond market and the stock market have little effect.
\end{abstract}

Key words: Shanghai and Shenzhen 300; corporate bond; co-integration test; Granger causality test; impulse response; variance decomposition

\section{Introduction}

The stock market and bond market, as the two important parts of the financial market, play an increasingly important role in the financing of the capital with China's economic development and national income level increase. Historically, the stock and bond markets have seen many typical "linkage" trends: between second half of 2008 to early 2009, the stock market continued to fall under the influence of the financial crisis, but the bond market moved out of the bull market at the same time. In 2013 June, as the central bank actively tightened liquidity, the stock market and the bond market plummeted. However, in December 2013 and early 2014, the banks released liquidity, but the stock market prices declined and the bond market unilateral upward. The stock market and the bond market sometimes change in the same direction, and sometimes reverse, showing the correlation between the stock market and the bond market, and it is this kind of correlation that can help investors to disperse the risk. Therefore, the study of the correlation between the stock market and the bond market has important practical significance for the construction of the investor portfolio.

Bossaerts ${ }^{1}$ (1988) found that if the economy developed into an independent balanced state, the stock market and the bond market would exhibit a dynamic change in the price differential at a fixed level. Peter and Wessel ${ }^{2}$ (2002) observed the weekly return of American stock 
market and bond market, and found that there was obvious conditional heteroskedasticity between the covariance of the stock market and the bond market. Shiller and Beltratti ${ }^{3}$ (1992) observed the historical relationship between the stock market and bond market returns between 1948 and 1989, and found that there was no stable correlation between the two markets.

In this paper, we use the covariance test of E-G two-step method, Granger causality hypothesis test and impulse response method to analyze the dynamic correlation between stock market and bond market.

\section{Research design}

\subsection{Samples and data}

The empirical research selects the data of the CSI 300 index and the corporate bond index from January 1, 2011 to December 30, 2016.In order to make the data match daily, the exchange rate and the CSI 300 index mismatch data are deleted, a total of 1455 sample data.The above data are from the flush database. All the empirical results in this paper are from the software Eviews8.0.

In order to eliminate the existence of heteroscedasticity, this paper carries out the logarithmic processing before the empirical analysis. In the empirical test, respectively use "LNSTOCK" and "LNBONDS" to represent the logarithmic processing of the Shanghai and Shenzhen 300 index and Corporate bond index.

\subsection{Descriptive statistics}

Table 1 Stock and bonds correlation coefficient

\begin{tabular}{|c|c|c|c|c|c|}
\hline & & \multicolumn{2}{|c|}{ BONDS } & \multicolumn{2}{|c|}{ STOCK } \\
\hline \multicolumn{2}{|c|}{ BONDS } & \multicolumn{2}{|c|}{1.000000} & \multicolumn{2}{|c|}{0.526563} \\
\hline \multicolumn{2}{|c|}{ STOCK } & \multicolumn{2}{|c|}{0.526563} & \multicolumn{2}{|c|}{1.000000} \\
\hline \multicolumn{6}{|c|}{ Table 2 Stock and bonds descriptive statistics } \\
\hline & Mean & median & Standard deviation & Skewness & J-B statistics \\
\hline BONDS & 127.8531 & 127.6900 & 2.289391 & 0.312588 & 54.30843 \\
\hline STOCK & 2889.507 & 2666.950 & 637.8966 & 1.182205 & 475.5271 \\
\hline
\end{tabular}

It can be seen from the table, both the CSI 300 index closing date or corporate bond index, skewness are greater than 0 , the kurtosis are greater than 2 , J-B statistics are far supercritical, they do not meet the normal distribution.

\section{Empirical analyses}

\subsection{Unit root test}

For the time series data, in order to prevent the occurrence of pseudo-regression, the first step is to test the data by unit root to see whether the data is stable. This article uses the most 
commonly used ADF test, the corporate bond index and the CSI 300 index are tested, the results shown in table 3 :

Table 3 ADF test results

\begin{tabular}{llllll}
\hline variable & ADF statistic & $1 \%$ & $5 \%$ & $10 \%$ & conclusion \\
\hline LNSTOCK & -1.432725 & -3.434639 & -2.863322 & -2.567767 & unstable \\
LNBONDS & -0.457427 & -3.434655 & -2.863328 & -2.567771 & unstable \\
D(LNSTOCK) & -36.79000 & -3.434642 & -2.863323 & -2.567768 & steady \\
D(LNBONDS) & -11.06556 & -3.434655 & -2.863328 & --2.567771 & steady \\
\hline
\end{tabular}

The results of the test shows that the ADF test value of the logarithmic sequence of the Shanghai and Shenzhen 300 Index is -1.432725 and the logarithmic sequence of the corporate bond index is -0.457427 , which is tested at the $10 \%$ significance level, So are non-stationary. While the t-statistic of the logarithmic first order differential sequence of the CSI 300 index and the corporate bond index are -36.79000 and -11.06556 respectively, and their absolute values are significantly higher than the critical value at the $1 \%$ significance level, so it can be considered the logarithm of the CSI 300 index and the logarithm of the corporate bond index after the first-order difference are stationary time series. Below we can conduct a cointegration test to test whether there is a cointegration between variables.

\subsection{Cointegration test}

Through the above unit root test, the first-order difference between the CSI 300 Index and the Corporate Bond Index is stable. The co-integration test is used to observe whether the CSI 300 Index and the Corporate Bond Index have a long-term equilibrium relationship. There are two commonly used cointegration tests, namely Engle-Granger two-step test and Johansen test.

This article uses the Engle-Granger two-step test. The first step: the use of least squares I (1)

on the two sequences $y_{t}$ and $x_{t}$ establish a long-term equilibrium equation:

$$
y_{t}=k_{0}+k_{1} x_{t}+\varepsilon_{t}
$$

The second step, the residual after the regression of the unit root test, if the residual $\widehat{\varepsilon}_{t}$ is passed the test, $\quad y_{t}$ and. ${ }^{x_{t}}$ are cointegration

Now, we first calculate the non-equilibrium error $\boldsymbol{e}_{t}$, a simple OLS regression, into the equation: 


$$
y_{t}=\alpha+\beta x_{t}+\varepsilon_{t}
$$

Bring in data that is $\ln E X B O N D S=0.0494874538934 * \ln S T O C K+4.45745227835$

Then the resulting residuals are tested by unit root to see if they are stable, and the results are shown in table 4:

Table 4 Residual ADF test

\begin{tabular}{llllll}
\hline variable & ADF statistic & $1 \%$ & $5 \%$ & $10 \%$ & conclusion \\
\hline RESID01 & -0.954278 & -3.434642 & -2.863323 & -2.567768 & unstable
\end{tabular}

As we can see from Table 4, the ADF statistic of the residual term is -0.954278 , which is non-stationary at the $10 \%$ significance level, that there is no cointegration relationship between the logarithm of the bond index and the logarithm of the CSI 300. So there is no long-term equilibrium between the logarithm of the bond index and the logarithm of the CSI 300 , and there is no cointegration relationship, we can not establish the error correction model.

\subsection{Granger causality test}

In order to find out the dynamic correlation between stock market and bond market, we conduct a Granger causality test on the CSI 300 Index and the Corporate Bond Index. First, we need to determine the optimal lag in the Granger causality test. We establish the first-order VAR model of logarithm of the CSI 300 index and the corporate bond index, and observe the optimal lag,the optimal lagged period of Granger causality test is 16.The test results are shown in Table 5:

Table 5 Granger causality test results

\begin{tabular}{llll}
\hline Null Hypothesis & Obs & F-Statistic & Prob \\
\hline DLNSTOCK does not Granger Cause DLNBONDS & 1438 & 1.64086 & 0.0521 \\
DLNBONDS does not Granger Cause DLNSTOCK & 1438 & 1.41544 & 0.1255 \\
\hline
\end{tabular}

From Table 5, in the $10 \%$ confidence interval, rejecting the original hypothesis, that is, corporate bond index is the CSI 300 index Granger reasons, but also can be seen in the $10 \%$ confidence interval, the Shanghai and Shenzhen 300 index is not the Granger cause of the corporate bond index. So there is a one-way Granger causality between the bond market and the stock market.

\subsection{Impulse response and variance decomposition}

Impulse response function, which represents the response of an endogenous variable to a standard unit error, uses the original sequence to establish the VAR model to find it stable, so the impulse response can be performed. The test results shown in Fig. 1: 
Response to Cholesky One S.D. Innovations ?2 S.E.
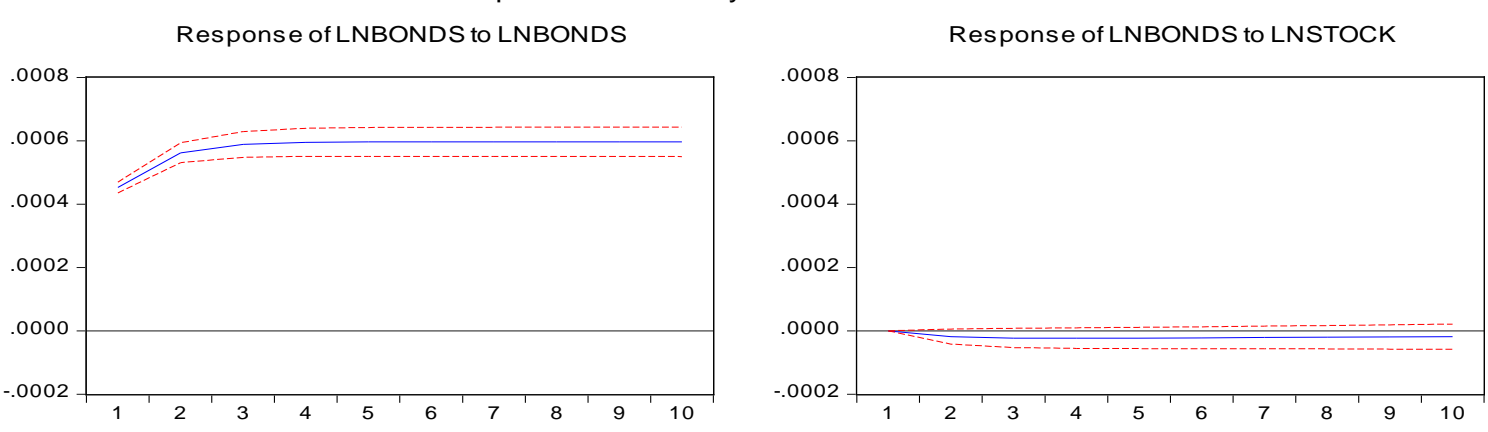

Response of LNSTOCK to LNBONDS
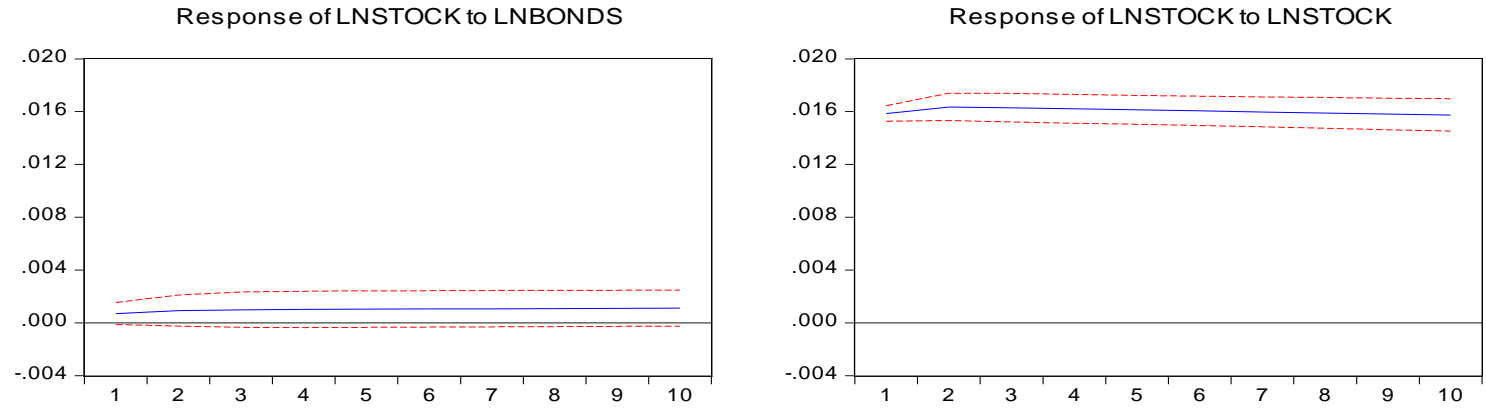

Fig. 1- Impulse response

Can be seen from the above chart, to the Shanghai and Shenzhen 300 Index a standard deviation of the impact, although from the first phase of the negative reaction and all the way to strong until the 10th period, but the whole is very small, only about -0.0001 , tend to 0 . And its response to the impact of relatively strong, from the beginning of the first phase, there is a positive reaction, more gently, about 0.016 fluctuations.In contrast, to the corporate bond index a standard deviation of the impact of the CSI 300 index response, although there is only positive 0.001 , but compared to its own response to the shock, far more than the corporate bond index, a standard deviation of its impact on the impact of its own large and stable.Then we look at the variance to observe the impact of different shocks on the importance of the model, as shown in Fig. 2.
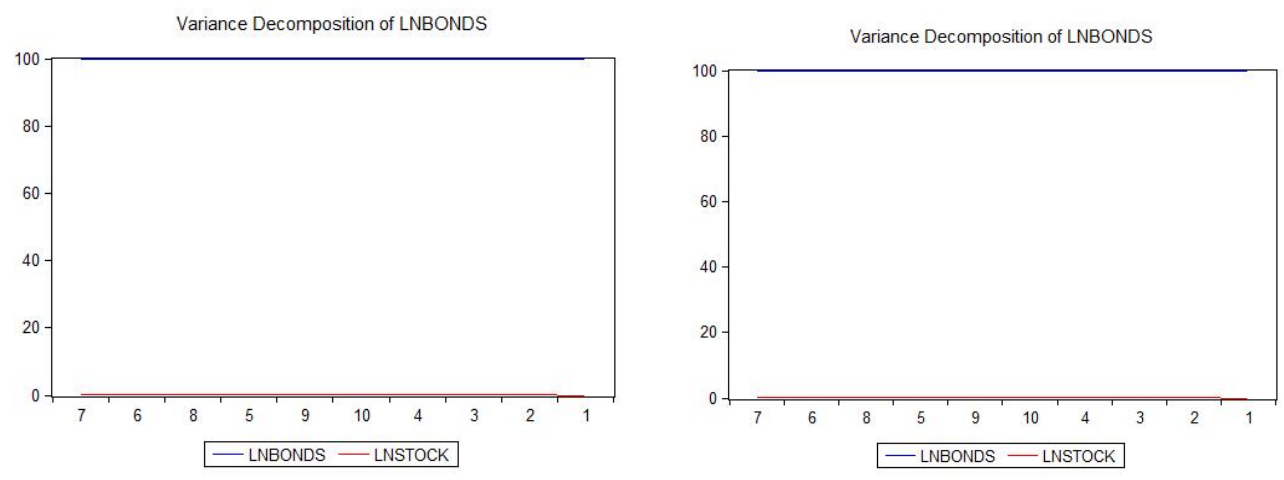

Fig. 2 -Variance decomposition

From Fig.2, we can see that the contribution rate of the CSI 300 Index to corporate bonds is 0 in the first period and the upward trend in the subsequent period, the highest is $0.126306 \%$ in the seventh period. Overall, the CSI 300 index has a very low contribution rate to the 
corporate bond index. As can be seen from Figure2, the contribution rate of the RMB to the US dollar on the Shanghai and Shenzhen 300 Index is also low, the highest is reached $0.396808 \%$ in the 10th period, so from the perspective of variance decomposition , the two contribute to each other are relatively small.

\section{Conclusions}

This paper chooses China's CSI 300 index and corporate bond index in 2011 to 2016 data as the research sample, using cointegration test, Grainger causality test and impulse response analysis method to analyze the dynamic correlation between the Shanghai and Shenzhen 300 index and corporate bond index. Through empirical analysis, the following conclusions are drawn:first, there is no cointegration relationship between the bond market and the stock market. Second, the corporate bond index is the Granger cause of the CSI 300 index. Third, from the perspective of impulse response and variance decomposition, there is no effect between the bond market and the stock market.

At last, we put forward the following suggestions:first, we should establish a unified, linkage of the bond market system. Reducing the threshold of bond access, so that some small and medium investors can participate in the bond market and gradually building the exchange market and OTC trading platform composed of multi-level bond market. Second, the establishment of multi-level stock market supervision system. We should pay attention to the system construction, improve the ability to prevent risks, strictly enforce the law, pay attention to correct and crack down on illegal acts, and effectively protect the interests of investors.Finally, we should continue to promote the market-oriented interest rate reform, improve the efficiency of monetary policy, so that the stock market and bond market can truly become a good platform for corporate finance and investor investment.

\section{References}

1. P.Bossaerts, Common nonstationary components of asset prices, Journal of Economic Dynamics and Control, 1988, 12(2-3): 347-364.

2. P. D. Goeij, W. Marquerig,Modeling the conditional covariance between stock and bond returns: A Multivariate GARCH Approach ,SSRN Working Paper, 2002

3. R. J. Shiller, A. E.Beltratti,Stock prices and bond yields: Can their comovements be explained in terms of present value models?,Journal of Monetary Economics, 1992, 30(1): 25-46.

4. J.Y.Campbell, J.Ammer, What moves the stock and bond markets? A variance decomposition for long-term asset returns, The Journal of Finance, 1993, 4891, 3-37

5. R.Y.Goyenko, A. D. Ukhov, Stock and bond market liquidity: A long-run empirical analysis,Journal of Financial and Quantitative Analysis, 2009, 44(01): 189-212 